Alderson P, Hawthorne, J, Killen M (2005) The participation rights of premature babies. International Journal of Children's Rights, 13:31-50.

\title{
The participation rights of premature babies
}

\begin{abstract}
This paper reviews the relevance of the UN, 1989 Convention on the Rights of the Child (UNCRC), and particularly the so-called participation rights, to premature babies and their care. The review is illustrated with examples drawn from a study of four neonatal intensive care units, NICU. The paper begins with the background on human and children's rights, on research about childhood, babies and participation, and on the neonatal research study. Participation rights include rights to: life and survival; a name, identity and nationality; contact with the baby's family; respect for the child's cultural background, and inherent human dignity; the child's right to express views freely in all matters affecting the child, the views to be given due weight according to the age and ability of the child; the opportunity to be heard during proceedings that affect the child; freedom of expression and information, of thought, conscience and religion, of association and peaceful assembly, rest and leisure, play, and to participate freely in cultural life and the arts; disabled children should enjoy a full and decent life and active participation in the community with the fullest possible social inclusion. The paper concludes that respect for babies' participation rights is feasible, immediate, integral and indispensable to adequate neonatal care, and that babies' rights justify and validate high standards of neonatal care.
\end{abstract}




\section{Introduction}

Is it appropriate or useful to phrase premature babies' needs, welfare, or best interests in the language of babies' rights? Can babies be rights-holders? This paper reviews the relevance of the UN, 1989 Convention on the Rights of the Child (UNCRC), and particularly the so-called participation rights, to premature babies and their care. The review is illustrated with examples drawn from a study of four neonatal intensive care units, NICU. The first part of this paper presents the background on human and children's rights, on research about childhood, babies and participation, and on the neonatal research study. Examples from the study illustrate how participation rights relate to premature babies. The paper concludes that respect for babies' participation rights is feasible, immediate, integral and indispensable to adequate neonatal care, and that babies' rights justify and validate high standards of care.

\section{Rights}

Rights are justified on two main grounds. Firstly, they may be seen as universal, inalienable to all members of the human family (the UNCRC is ratified by all governments except in the USA and Somalia) and legal entitlements that defend and respect every citizen. Citizenship from birth entitles the child to a legal identity, and the right to expect certain services, protections and amenities from the state. Babies can easily be included in these concepts of rights. Secondly and alternatively, citizenship with its civil rights may be justified as a status that is gradually learned or earned or developed towards, and is granted by age, sex, or merit. Traditionally, English law has restricted children's rights and regarded children up to 21 and more recently 18 years as legal "infants", literally "not speaking". Current English policy on citizenship education (QCA, 1998) slips uncertainly between education for future adult citizenship or the education of children who are citizens now. Traditional links between a set age of majority linked with citizens' participation or civil rights and the key right to a voice and to freedom of self-expression were replaced during the 1980s by competence or maturity. English case law now respects the decisions of children who have the understanding and discretion to make informed and wise decisions in their own best interests Gillick [1985]. The UNCRC accords to children who are able to form and express their own views, "the right to express those views freely in all matters affecting the child, the views of the child being given due weight in accordance with the age and maturity of the child" (UNCRC, 1989: 121 ${ }^{1}$. Neither article 12 nor Gillick states a minimum age, and these standards lean towards Holt's view (1976) that children should be able to exercise their rights when they become able and willing to do so. Does the ability-competence criterion open all children's rights from the above second concept of age-based rights towards the first universal concept that embraces all members of the human family? And are even premature babies able to form and express their own views?

In Britain, the fetus is legally not "a person" (Montgomery, 1997:401) and has no rights throughout the 40 or more weeks of pregnancy, except for one right after 24 weeks: ${ }^{2}$ protection from termination of pregnancy. This right to life, however, is qualified in three ways. Firstly, termination is allowed up to term if "serious handicap" is detected (1990 HFE Act). Secondly, in 2002 for example, although 2,753 abortions between the $20^{\text {th }}$ and the $24^{\text {th }}$ week were recorded, gestational ages may be underestimated in records to allow abortions after 24 weeks (Times 8.9.03). Thirdly, practitioners are advised to respect women's refusal of interventions during pregnancy and labour, including interventions intended to save the life of the fetus (RCOG, 1994).

\footnotetext{
1 Numbers in brackets refer to UNCRC articles.

2 "Weeks" indicate the length of gestation.
} 
In marked contrast, from birth children are entitled to legal personhood, partly denoted by the complex and comprehensive UNCRC rights. The UNCRC preamble recognises the importance of special care within the family for the immature child in "an atmosphere of happiness and love and understanding" although these cannot be rights because they cannot be willed or enforced. UNCRC rights are qualified in that "the best interests of the child shall be a primary consideration" (3), taking account of the rights and duties of parents or other responsible persons "to provide, in a manner consistent with the evolving capacities of the child, appropriate direction and guidance in the exercise by the child of the [UNCRC] rights" (5).

Premature babies can easily be seen as benefiting from their UNCRC provision rights to services, to health care, education (of their parents and carers), welfare and amenities (Alderson in press). Babies clearly benefit from their UNCRC rights to protection from abuse, neglect, violence and discrimination (Alderson forthcoming). These rights can equally well be considered under the traditional rubric of the need, welfare or best interests of the child. The UNCRC participation rights are different, in being moderate versions of adults' autonomy and civil rights, and some of these are often considered to begin to be relevant to young people aged from 10, 12 or 14 years. Participation rights include qualified freedoms of expression, information, thought, conscience and religion, association and peaceful assembly, set out in articles 13-15, which are subject to the "national law, public safety, order, health or morals or the protection of the rights and freedoms of others". A further constraint is that although English law in Gillick respects the decisions of competent children, the UNCRC leaves the final decision making to adults and asks adults only to give "due weight" to the child's views according to age and maturity (12). Some participation rights relate more obviously to babies: the right to life, to a name, an identity, a nationality, children's rights to have contact with parents and family, to respect for their worth and inherent human dignity as valued members of society, and to respect for their cultural background. All the UNCRC rights can relate to young children (Alderson, 2000), and this paper will consider how the participation rights also relate to premature babies who survive birth from as early as 22 weeks gestation. The next section reviews insights from research about children's and babies' competencies and abilities to participate in their care and relationships.

\section{New understandings of childhood and babyhood}

Traditionally, children have been viewed as pre-social beings, who are developing and being socialised by adults towards the endpoint of mature adulthood (Mayall, 2002:4-5). The positive concept of development, of gradually becoming more informed, skilled, rational and reliable, has an inevitable negative converse side: deficit models of younger children as ignorant, incompetent, pre-rational and volatile. However, researchers have increasingly questioned this deficit model, and have examined how childhood is socially constructed, defined and practised in different societies. They have asked: how and why adults construct children as noncompetent (as women used to be constructed); how young children's essential vulnerable dependence may be increased by ascribed and taught incompetence and helplessness; how adults' interests and authority are served by keeping children in an often imposed and prolonged dependence, which countless children around the world and in the past have shown is neither inevitable nor essential (John, 2003). Just as concepts of gender inequalities have been key to understanding womanhood and women's social status, so "the concept of generation is key to understanding childhood" (Mayall, 2002:120; Alanen, 2001), to see how childhood is socially constructed through numerous changing beliefs, behaviours and adult-child relationships (James and Prout, 1997). Detailed observations show how young children can be highly competent - technically, cognitively, socially and morally (Dunn, 1987; Gardner, 1993; Hutchby and Moran Ellis, 1998; Alderson, 2000). More than being actors, young children can be agents: people who negotiate with others, 
and alter relationships or decisions or the working of social assumptions or constraints (Mayall, 2002:21). Researchers therefore have questioned the assumed gradual ascent from zero at birth up to adulthood.

Since the 1960s, psychologists have recognised newborn babies as "agents creating their own environments in interactions with their caretakers" (Bell, 1968 cited in Wolke, 1995:117). Babies contribute to the parent-infant dyad and to their own development. They seek comforting stimuli, and avoid and shut out unwanted stimuli by habituation (getting used to and coming to ignore repeated stimuli) and by going to sleep. They have a range of self-soothing behaviours, and they "speak" in an expressive language of sounds, facial expressions and body movements that can be "read'. Babies vary greatly in how far they have a robust capacity to learn to handle multiple stimuli, to organise themselves, to interact with the complex environment, and to control their states so that they can avoid becoming overwhelmed and disorganised. Babies also vary in how cuddly they are by nestling or moulding themselves against the carer's body, and in how readily they take part in social interactions, turning to sounds, tracking, gazing, smiling and becoming excited or irritable, as well as how soon they become exhausted, which they signal by becoming pale or mottled, with altered breathing, hiccoughs, yawns and regurgitating or gagging and crying (Brazelton, 1961; Brazelton and Nugent, 1995; Murray and Andrews, 2000).

Researchers' deeper awareness of newborn babies' "marvellous" and "amazing" capacities has followed two key insights, which treat assessment as a means of participating in social interaction. First, observers must always take account of the baby's state or level of awareness, from deeply or lightly asleep, to drowsy or alert, to becoming upset or crying intensely (Brazelton, 1961). Second, observers must be self-aware and receptive, moving beyond a distanced objective view that treats the baby as an object, towards experiencing a dynamic personal emotional interaction with the baby, sensitively following each baby's cues to help them to give a "best performance". "New born infants are social beings who quickly learn to judge the safeness of a situation from the examiner's facial expression and voice, as well as from the way they are handled" (Brazelton and Nugent, 1995:2, 11). The NBAS Neonatal Behavioural Assessment Scale - systematically documents term babies' responses to aversive and non-aversive stimuli, and scores behaviours taking careful note of the baby's states. Babies' behaviour is recognised not as wholly biological, driven by instincts and genetically programmed development, but also as social, learned and responsive (Vygotsky, 1962; Bruner, 1990; Fifer and Moon, 1994; Siegal, 1997). "Nurture" shapes "nature", when individual's experiences alter the structure of the brain, before and after birth (Shatz, 1992; Greenfield, 2000). Research interest has grown in how babies "participate", "take part" and are "partners" in their learning and social relationships.

These participatory approaches have been applied to preterm babies "as socially competent and active partner[s]" with their caregivers, "seeking and eliciting" interactions "to assure self-actualization", and actively shaping their own development; "self-actualization is participation with the world and interaction with another... with a maximum of joint validation" (Als, 1999:31, 33, 35). NIDCAP Newborn Individualized Developmental Care and Assessment Programme - involves naturalistic observations of even the smallest most fragile preterm babies from the first week after birth to record the baby's strengths and sensitivities (not deficits) and to identify goals and recommendations for care (Als, 1981). Babies' behaviour or language is understood in three subsystems: autonomic (breathing, heart rate, skin colour, hiccoughing, regurgitating); motor (body tone, posture, facial and body movements); and state (patterns of transferring between the states described earlier) (Als, 1981, 1999). NIDCAP sessions last at least 60-90 minutes and observe the environment and the baby's behaviours and interactions with carers, in order to 
educate and support the caregivers and to plan care that will enhance the baby's wellbeing and competence.

As this brief review indicates, decades of evidence-based recommendations have been derived from forms of participative research that meticulously observe and listen to babies and try to perceive their views and learn their language. Whereas the fetus floats in warm fluid, gently bumping against the sides of the uterus, sensing muted sound and diurnal light, and not needing to feed, or digest, or breathe, or cope with gravity and temperature changes, premature babies have to learn to manage without all these protections before they are ready to do so. Premature babies also have to cope with high levels of light, noise, and painful procedures in some NICU, where lighting levels may sometimes be 40 times brighter than the recommended level for adults' office lighting (Glass, 1988), and the noise may be 120 decibels, well above the maximum 50 decibels recommended for offices (Graven et al., 1992). Compared with babies at home, babies in NICU have much less cuddling, comforting, and care from a few adults who can give sensitive individualised responses to the baby's cues described above. At times during the first forty weeks, the human brain grows by 250,000 neurones per minute (Purves, 1994), and there is particular concern for how the immensely rapidly growing premature baby's brain can best be protected and nurtured, by adapting "neonatal caring routines to the autonomy of the infant" (Lagercrantz, 2003). There have been long debates on whether premature babies should be treated more like a fetus or like a term baby, and whether they are over-stimulated by direct sensations in the NICU that would be muted in utero, or else are under-stimulated by missing the gentle sounds, colours, lighting, tastes, touch-sensations and free movements that the fetus enjoys. Wolke (1989) concludes that babies are both over-stimulated when bombarded with adverse stimuli and also miss comforting contingent stimuli responsive to their own cues and needs.

There are many practical recommended ways to increase premature babies' participation in their health care, development and relationships. For example, from 24 weeks, babies tighten their eyelids and from 30 weeks they close their eyelids in response to bright lights. Subdued lighting helps babies from around 32 weeks to interact with carers when they fix, track and gaze. The baby's gaze promotes parents' affection, "launching both partners on their path of complex affective and cognitive interchange, fuelling mutual competence" (Als, 1999:31). Babies have fewer disruptions to their breathing and heart rate and fewer startle reactions when noise is managed with appropriate acoustic design and the staff work quietly (Mann et al., 1986; Philbin et al., 1999). If premature babies lie supine with their limbs outspread, it is harder for them to do their main tasks: to breathe, to conserve energy, to sleep, and therefore to be able to feed and grow. They struggle against gravity to gather themselves together into the fetal position, limbs together, hands near face so that they can settle themselves, by bringing their hands to their face or sucking their fingers. Some neonatal staff take care to help babies to find and stay in their preferred position, by tucking them into soft fabric nests or rolls (Als, 1999; Boxwell, 2000:30-34). From 32-34 weeks, babies can coordinate their breathing, sucking and swallowing while learning to feed (Goldson, 1999). Care that is consistently responsive to the individual baby's cues helps to prevent babies from becoming stressed, disorganised and unstable, while promoting rewarding interactions between babies and carers (Gottfried, 1985). Care needs to be synchronised with each baby's signs of strength and sensitivity, seen in behaviours that are characteristically either approaching and exploring or avoiding and withdrawing (Als, 1999:33). Skin-to-skin holding ("kangaroo mother care") benefits the baby and parent, stimulates breastfeeding, and promotes health and earlier discharge, its advantages have been demonstrated by research, and it has been predicted to "become the standard of care throughout the world within 10 years" (Anderson, 1999:152). 
NBAS and NIDCAP promote appropriate care for babies individually and also generally when they are used to evaluate NICU standards, and to plan new structures and systems. Yet despite randomised research evidence of the advantages of what might be termed "baby-led" policies, many NICUs still disregard this evidence or say that it is too weak. Whether neonatal staff spend time interacting with the babies appears to depend rather arbitrarily on how important the staff consider this to be, regardless of staffing levels, and also on how much individual babies initiate vocal and visual interactions (Linn et al, 1985). Goldson (1999:3-4) notes that although all members of the highly trained neonatal team are committed to each child's survival and optimal development, "yet they function and perform their work in environments that may not be conducive to their own well-being or to the well-being of the infants they are committed to be caring for." White (1992) asks why "noxious" NICU continue to be built. Goldson (1999:13-14) deplores the lack of research-based practice in many units, and speculates on whether this neglect is related to systems-based rather than individual-based models of care, that set the convenience and working needs of the staff before the needs of the family, besides cost and space constraints. The following sections review and illustrate specific participation rights, after explaining the research from which the examples are drawn.

\section{The neonatal research}

An ethnographic study, 2002-2004, observed four NICU in southern England (Alderson et al., 2004). Semi-structured tape-recorded interviews were held with 40 senior neonatal staff and, in the units and in their homes, with a purposive sample of the parents of 80 babies at risk of neuro-developmental problems. The research investigated: how relatively new neonatal treatments, techniques, knowledge and ethical guidance complicate or illuminate long-standing neonatal dilemmas; how clinicians select, evaluate and manage the many neurologically related issues, when making diagnoses, prognoses and treatment plans, and when discussing these with parents and colleagues; how parents and babies experience and respond to the NICU; the strengths and gaps in current knowledge and practice; and how multidisciplinary insights can inform care that is in babies present and future best interests. The transcripts and observation notes were analysed for replies to the research questions and for themes raised by participants (Strauss and Corbin, 1998). The data were analysed qualitatively, not in order to test a hypothesis or to measure incidence, but to analyse and try to explain current policies and practice. This paper analyses the data in the light of child rights perspectives.

\section{Participation rights}

\section{The right to life (6)}

The first participation right, from which all others follow, is that "every child has the inherent right to life [and] to the maximum extent possible survival and development" (6). The rights to life and to protection from torture (37) are commonly counted among the few absolute rights. Sadly, for premature babies neither right is absolute, partly because they can conflict. Several neonatal staff referred during their interviews to painful but life-sustaining treatment sometimes as "torture". The right to life as survival can also potentially conflict with the quality-of-life rights: the right to the maximum extent possible of development (6), to the highest attainable standard of health (24), and to an adequate standard of living (27). Andrew was born at 22 weeks, and his parents were asked to decide if his treatment should continue. "We said we found the decision a very difficult one to make, because if he did survive we might be imposing a lifetime of suffering on him" (research number 1.20). So if a baby seemed to be very unlikely to survive, or to gain from painful treatment, or to have a future without severe suffering and serious impairment (in re B [1981] 1WLR 1421), the adults began to discuss whether treatment should legally be withheld or 
withdrawn, and the baby be allowed to die, as debated in an extensive literature (RCPCH, 1997; BMA, 2001; McHaffie, 2001).

The usual policy at birth in Britain, if the baby appears to have some hope of survival, is to provide any necessary life-sustaining treatment in order to allow time to conduct tests and enable senior practitioners and parents to share in making informed decisions. NICU vary in the age of viability that they will accept; fewer units admit babies aged less than 24 or 23 weeks. Practitioners refer to a window of time while the baby depends on mechanical life support and it is still possible to decide to withdraw treatment. If the baby survives long enough to breathe independently, a decision to end life alters from "allowing the baby to die" by withdrawing mechanical ventilation into, more controversially, withdrawing fluids and nutrition.

Medical ethics is influenced by high expectations of the threshold for a "reasonable" quality of life free from impairment and for an intellectual form of personhood, and low expectations of babies' capacities and awareness. Harris (1985) asserts that no babies can value their own life and therefore their life has no value. Singer (1995) and others regard babies as non-persons (and therefore non-human-rights holders), lacking five "ethically relevant characteristics": consciousness; the capacity to interact with others; having conscious preferences for continued life; having enjoyable experiences; and having relatives who will grieve at their death. In response, Wyatt (1998: 167-8) describes the many parents he has known who relate to their premature baby as a unique, precious member of the human community, an individual, with a history, an identity and a name, not a thing but a person to be treated with gentleness and respect, irreplaceable, a beloved child.

There are four criteria and kinds of evidence for considering whether babies are persons with human rights to life. Firstly legal, all babies from birth are recognised as persons with rights (HRA, 1998; UNCRC, 1989). Secondly societal, although society gains economically from treating impaired and unwanted babies as expendable, it is debated whether these cost-effective values increase human happiness and wellbeing, though that is a topic beyond this paper. Third is the value of premature and impaired babies to their parents and other carers, and our interviews and observations confirmed the overwhelming view in the empirical literature that these babies are very highly valued, loved, and grieved for; if withholding treatment is reluctantly considered, the primary concern is the best interests of the baby. Fourth are the rarely reported babies' own experiences and responses, and adults' perceptions of these, reviewed in this paper.

The right to life is often discussed as if this is something that adults allow or support, and babies receive. However, many premature babies put much energy and concentration into surviving as if, consciously or not, they value their life. When William (all the babies' names have been changed), born at 30 weeks, was aged 9 months, his mother was interviewed while she bottle-fed him. He still had a look of intense anxious concentration as he managed his breathing and struggled to suck and to cope, it seemed, with a bloated feeling after each short feed. Like some other babies, from soon after birth William gazed at his mother's face, as if he depended on her loving support. The pleasure or reassurance that some babies evinced when held by their parents or by nurses they knew well showed that, to some degree, they had all five of Singer's above "ethical" characteristics.

Interviewer: And was there anything in him do you think that helped to get you all through [the time in NICU]?

William's mother: I think they're amazing... babies, generally... a lot of the conversations between the [other] mothers come back to this, that they look very frail but they're not - determined little - the will to live, I mean it's obviously not as conscious as that in a baby, but the life thing is so strong, they'll fight and fight and fight and you start respecting them for that, you know, he's been much iller than l've ever been - never had me in intensive 
care, but they kind of keep going and you end up feeling really quite in awe of that (research number 3:15) [ - means pause, ... means words omitted].

Many parents and practitioners described similar admiration, and gave examples of babies continuing to survive against all expectations, or sometimes unexpectedly "giving up" as if, in some ways, the babies had the final say in whether they lived or died.

\section{The right of a child to a name and nationality (7) and to preserve his or her identity}

(8)

The baby's first name is a crucial way to enable everyone in the NICU to identify and relate to the baby as a unique person. The family name denotes the baby's family membership, history and, often, ethnicity. Some first names are significant as the names of loved relatives, or they describe the baby. "Yemi's" elder sister had lived for only one day, and he was born at 24 weeks with a 20 per cent chance of survival, after a delayed journey in an ambulance that got lost. He stayed in the NICU for 6 months. His mother said: "His real name means 'remembered by God'. I thought how appropriate because he could have been born on the steps of the flat, so I always think God was watching over him" (2.20).

Babies participate by sustaining and rejuvenating and assuring the future of their society and nation. Having a name and a nationality enables the child to be registered, and therefore to be entitled to the UNCRC rights because these entail recognition by "state parties". Babies are then entitled to state services such as free neonatal care in Britain.

"Identity" refers to personal characteristics and agency. Adults frequently described babies' distinctive responses and contrasted these with the characteristics of other babies or siblings. James was born at 31 weeks and was on cpap, a breathing aid. Some babies pulled on their tubes and the medical notes often recorded "selfextubated". James's mother described how he guided her caring:

He doesn't like cpap he pulls it out sometimes, he has pulled all his tubes out and then he is really happy when everything is out and he can be his own person. Yes I see him as a person, sitting and watching him for hours, learning about what he likes. He likes lying on his left side on his tummy, not on his right side. And he's also like his father, he dislikes anyone playing with his feet, even if he's sedated if you touch his foot he'll squiggle but he likes his head and chin and forehead and his back being stroked. If he's on his right side he gets grumpier. You can learn more and more about your own baby...Stroking him does sometimes help, and talking to him, that sometimes stops him crying, but I have to be careful not to get him too excited because then his respiration rate goes up...You're projecting things from yourself and when he is awake and in a bad mood I see a lot of fighting spirit... If I talk to him such as while he is having blood taken, he calms down (3.4).

One doctor described seemingly lasting identity or characteristics when as children grew older they continued to be the "good" girl or the "extremely feisty" boy, and added: "There seem to be some very tenacious very strong characters....and they seem to be babies who do clinically very well" (1.24).

Another aspect of "identity" is personhood, and we picked two qualities, memories and emotions, to see if parents and practitioners believed that babies were beginning to be "persons" of the kind that philosophers might recognise. Several practitioners denied this possibility, or said, "I hope not", as if neonatal care would be less painful for babies without memories or emotions. Research by Brazelton, Als and others records specific emotional capacities. During our observations and interviews we saw, or heard adults describe, babies who appeared to express hurt, misery, calm, 
contentment, relief, pleasure and excitement. One counsellor's views were shared by several neonatal colleagues:

Yes I definitely think they have emotions and memories. I think they definitely know the difference between the touch of a parent and the touch of a nurse or a doctor, and...that if a parent touches them that's going to be a loving touch and caring touch. The businesslike touch of a doctor is going to be very different. One can almost see the child cringe or tense...You see the difference in the reaction when the parent arrives there is an excitement it's incredible but it may sound mad but I do think having been looking at the babies for so many years when their parent arrives the number of times l've said to the parents, "They know you are here, they are excited to see you they are pleased." You can actually tell these things from a 23 weeker, which is amazing. And of course they have a memory, I think they understand whether they are going to have an [intervention]. I think the memory... is unthinkable but it's knowable (1.25).

To recognise babies as sensitive persons with these kinds of memories and emotions raises vital questions about how neonatal care can respect babies' rights to "preserve" their identity.

The right to contact with family and parents $(5,7,8,9,10,11,18,20,22,24,27) A$ child shall not be separated from his or her parents against their will, except when [this] is necessary for the best interests of the child (9)

The UNCRC, far from being a vision of selfish competing rights, repeatedly emphasises participation: solidarity, equality, communities of peace and justice, and rights that are respected through relationships, beginning with the family. The UNCRC respects "the responsibilities, rights and duties of parents" (5). Besides having "contact" with their family, babies actively contribute: they create and perpetuate families by enabling their parents to realise the right to "found a family" (HRA, 1998). The attachment between children and parents, central to family life, appears to be especially nurtured by close physical contact between parents and the active social baby during the early weeks and months (Odent, 1999; Murray and Andrews, 2000; Matthiesen et al., 2001).

Parents believed that their babies knew them early on.

Joe's mother: I really think Joe worked out who I was very early on...there'd be people around him doing things... and then l'd walk in the room and start talking and it was obvious that he looked towards my voice... and change and get a bit excited, get a bit jumpy...(1.12).

Chima's mother: Even when he is sleeping and I come in, he opens his eyes and looks around. I think he knows my smell or something (3.3).

For babies, "contact" means close emotional and physical ties. The staff varied in how soon and how enthusiastically they encouraged parents to touch and hold premature babies, and helped parents if they were afraid of harming their baby. Some nurses believed that skin-to-skin cuddling made babies too cold and stressed, in reverse of the research evidence. Although parents tended to accept their own unit's policies, not knowing of possible alternatives, some were disappointed to have missed earlier opportunities, and others had to ask the staff to allow such contact. This could be hard when parents felt the staff might disapprove, or would criticise, or possibly blame parents if problems arose from their initiative. Adults might be more confident if they regarded this contact as the baby's right. Although soft cotton clothes and covers "facilitate restfulness and comfort" (Als, 1999:55), in some NICU, 
the babies are nursed nude and stay in incubators to keep them warm. In other units, they wear clothes and hats, and are moved out of incubators as soon as possible, promoting closer contact between babies and caregivers. James's mother described the link many parents made between contact as touch, relationship, and communication.

It would be impossible for me to wait four weeks before touching him as some parents say they do. How could you build a relationship with your child? When you take him out and cuddle him, the mother or the father, you are fully involved, he calms right down (3.4).

Over time, baby-parent contact alters some parents' views and experiences of the family. Henry's mother described how she grieved and mentally had a "tough hard time" because he had Down's syndrome, but how also they had a "wonderful" first year together: "he is a real blessing to me". She would not wish to change Henry because "if he didn't have Down's syndrome he wouldn't be the same person" (3.1). She spoke of her son's practical and emotional agency. He had transformed her life, for example, she did not return to her career as she had planned. And when asked what was the best and most helpful part of the neonatal unit, Henry's mother recalled the nurse who said to her, "These children they choose their parents, and this child has chosen you." Rather like the counsellor's view earlier, that babies' memory is "unthinkable but knowable", Henry's mother believed that from the start "he probably felt loved, some very prime, primordial, what's the word, deep way, they pick these things up, babies, they are very aware."

During the most private period, after birth, families have to cope with being in the noisy public NICU, and they need ways that help them to relax, to overcome separating barriers, and sustain intimate contact: curtained alcoves, reclining chairs, rooms for parents to stay and to eat, recognition of fathers' responsibilities (UNCRC: 18; Killen et al. forthcoming) help with transport, cots for twins and triplets to share as soon as possible. NICUs' provision of these facilities varied widely. The access and support can be seen as practical respect for babies' rights to tactile family contact that promotes babies' restful sleep and stable breathing, and parents' calm fulfilment (Als, 1999:55).

\section{Freedom of association and peaceful assembly (15)}

Respect for the child's cultural background, and inherent human dignity $(30,31,37$, 39)

NICUs restrict general visitors' access in order to preserve quiet and privacy, and some units limit parents' access. After the babies go home many parents avoid groups and family gatherings for fear of infection. Parents often found it hard to talk to relatives who did not understand their intense anxiety, and they appreciated sharing support with other parents in the unit, although some units discouraged this when, for example, parents were told not to look at or ask or talk about other babies, no parent support group was arranged, and mothers spoke of meeting to talk only outside the unit. So while they would most appreciate support from their extended family and welcoming ceremonies to affirm the child's cultural background and dignity as a valued new member of the family, parents could feel isolated, as Iwu's Nigerian mother described.

I go to see my baby and the nurses say, "Oh no you can't see your baby, it is not allowed, you know." Yes. If you ask anything about the next baby they say, "Don't ask, we don't have permission to talk about that, everything is confidential you know..." And you cannot go in to see the baby unless you are with the baby's parents, and so I have to take the family visitors in and be there with them, not friends I don't want them to come in to see her until she 
is well and everything is ok for her, they come to see me here [maternity ward]. Yes, I do need to see them. On Sunday a lot came, so even the staff had to ask them, "Oh you know this visiting time is over" [laughs] (3.5).

There are important reasons to limit and defer some of these participation rights but they are noted here as a reminder of some of the extra difficult differences that parents and babies experience after premature birth.

The child's right to express views freely in all matters affecting the child: the views of the child to be given due weight according to the age and ability of the child (12)

The key participation right, to express views freely, involves being able to form views and having the means of expression, and this section begins with expression through the body and the voice. The baby's cry could be highly significant to parents. Anna's parents had one living daughter and their three other babies had died. Anna was born by caesarean section at 26 weeks weighing only 500 grams, and her mother heard Anna several hours before she could go to see her in the NICU.

She cried when she was first born which we heard, which was pretty amazing, absolutely wonderful...her cry, which was something we thought we'd never hear, it was amazing. Absolutely amazing, it was lovely...they said she's got 50-50 chance of survival (4.1).

Although they find it distressing, parents are pleased when their baby grows strong enough to cry. "It's nice you can tell when he really has got the hump" (2.1).

It is not very easy when he cries but I also know that it is nice that he can cry. It was eerie.... with all the babies on ventilators... at least they can cry when they are off the ventilator. It is a nice sound, human, not that I want him to be in pain...it is more that they cry when they don't like something. They tell you (3.4).

Parents appreciate the nurses who comfort crying babies whose parents are away. Paediatricians are advised to read the babies' appearance and behaviour, for example, in order to assess and relieve their pain $(\mathrm{RCPCH}, 1997 \mathrm{a})$, which many practitioners take care to do, such as when a nurse talks gently and soothes the baby while a doctor inserts a line. Babies appear to distinguish between the gentle and painful simultaneous touching (Murdoch and Darlow, 1984) and noticeably cry less and quieten sooner when supported in this way. Not all staff are trained and supported to do this and some nurses hold a baby's arm still, do not look at the crying baby and walk away when the doctor has finished, while the baby cries, sometimes for long periods. The units differ in how far they give "due weight" to babies' basic expressions of distress or pleasure. Babies are most vocal in special care, the final room before they go home, which in some units resounds with frequent crying, whereas in other quieter units nursery nurses and parents spend hours cuddling and soothing the babies (Warren, 2001; Bond, 2002). The babies' expressed views on feeding are central to their healthcare, reviewed in another paper (Alderson forthcoming a).

When making the most serious decisions, adults might give, or have to give, "due weight" to the baby's "views" (however loosely these might be "formed"). Anna's mother described how twice Anna had rallied, contrary to the doctor's warnings.

And I feel so sorry for him [doctor] because it's like she's calling him a liar [laughs], which I am very pleased about. [Once, before the doctors could put her back on the ventilator, Anna's breathing rate suddenly improved.] It's like 
she's playing games with us here! [And she's saying] "I'm going to prove them wrong. I'm going to be okay" (4.1).

Anna's parents decided that they could cope with a child with learning difficulties. "What we can't cope with is no child at all." But eventually they agreed that if Anna's breathing failed the doctors would try re-ventilation, despite the extremely low chance of her survival, though they would not attempt resuscitation if her heart stopped. "Stubborn yes, and she fights hard for her - to sort of get better [but] if her heart was to stop beating that's her way of saying, 'I've had enough. I can't cope any more'“ (4.1). Anna died when she was 4 months old. It cannot be certain that babies "choose" to live or to die, still less express a choice by doing so, but neither can it be proved that they have no views on how long they continue the effort to survive when they are extremely weak and ill, or why some babies surmount far greater problems than others mange to. Some parents attributed outcomes partly to their child's view and personality.

Andrew's mother: Yes, I think he definitely chose to live, because there were a couple of points where I would have exited. I have to say I would have left this life... He was incredibly ill...he was dying effectively, and the doctors were saying that, "You know it's not good," and I kind of got this feeling that he had decided, "No actually I am not ready to go. I want to live," because then he would come back in from his sort of dying, and he would be fine. Well not quite but he would be different, and I feel that he chose to live...he's just incredibly determined (1.20).

Some neonatologists similarly spoke in terms of babies' agency.

Int: Do you think there are qualities in babies that help them?

1.23: I think it is remarkable. I have enormous respect for these little babies, and sometimes the way they cling on to life is extraordinary. I don't

know... this will to live somehow...A-- nearly died about three or four times. It was extraordinary how this little body, this little soul kept winning through. So yes, I think there are but I don't know how to describe that quality but I think it is remarkable.

An important "view" that many babies expressed clearly was their preference to be cared for by their parents and by certain nurses, as if the emotional relationship of care mattered as much to them as the activities of care.

There are certain nurses that know an awful lot about Sean, and are very fond of Sean, and Sean is very good when they are looking after him. And there are other nurses that [pause] I would say he picks up on their mood, and if they're not as confident with him as some of the other nurses, he does pick up on that, and he gets a bit upset. And I have noticed that quite a lot with him... Most of the time you know when he doesn't want you to touch him, especially when he cries, but there are there are certain nurses that he - it's kind of, it's hard to explain, you do feel like he's taking a certain amount more from some than others... (2.1).

When he was two months old (born at 25 weeks), Sean's mother described his communication. In some units, babies are bathed quickly, but in others the babies set the pace and are wrapped in a sheet at first, until they show when they are ready to enjoy the water (Warren, 2001). 
He's a very fussy little boy...even when he was in an incubator and he had a tube down his throat...you would soon know if there was something that he didn't like, so he's a good communicator... one minute the hands are out there to say "stop", and the next minute he's crying cos he wants to be picked up, so he's very finicky. [During his first bath] he was wrapped up for it but he pretty much decided to degown himself. He enjoyed it. He was amazing, so relaxed, and he cried when I took him out (2.1).

Countless observed and reported examples in the four NICU showed that many adults were convinced that they were not mechanically caring for the unconscious organisms that some philosophers allege babies to be. Instead, they were interacting within human relationships influenced by the babies' views. They confirmed Fischer and Rose (1994): "Because an infant is seen as continuously and actively selfconstructing, the task of care becomes one of collaboration with the infant...by actively interpreting an infant's behaviour, one can construct an appropriate caregiving environment [with] even the earliest, most fragile infants." Als (1999:35-9) advises that repeated detailed observations and records "may then form the basis for care giving suggestions and modifications in environmental structuring". The records see "the infant as an active structurer and participant in his or her own development," with care guided by the infant's needs and efforts, not purely the practitioner's plans. Als gives the individual example of adjusting the ventilator settings when the baby is trying to breathe with rather than against the machine. General conclusions may also be drawn from the babies' views, and from skilled observations, to inform NICU-wide policies to create baby-friendly units when practitioners respect and trust babies and parents (Als, 1999:58).

The opportunity to be heard directly or through a representative during proceedings that affect the child, and periodic review $(12,25)$

Freedom of expression and information $(12,13,23,24)$ of thought, conscience and religion (14)

Disabled children should enjoy a full and decent life in conditions which ensure dignity, promote self-reliance and facilitate the child's active participation in the community with the fullest possible social inclusion (23)

These articles endorse babies' rights, through their parents and other caregivers, to the regular and free exchange of information, so that whenever possible reviews, assessments, plans and decisions may be made that take account of babies' ascertained views and the values of the family. Article 23 partly resolves the potential conflict noted earlier between rights to survival and to an adequate standard of living, by advocating disabled children's fullest possible participation, an aim to which neonatal treatment and preventive care are dedicated. Parents and practitioners are assisted in being informed advocates for premature babies when they have multidisciplinary training and support, libraries and other "access to information and material from a diversity of national and international sources, especially those aimed at the promotion of [babies'] social, spiritual and moral well-being and physical and mental health" (16).

\section{Conclusion}

This paper has aimed to illustrate the relevance of participation rights to all children, by showing their relevance to those most likely to be excluded, premature babies. Examples from the NICU illustrate how respect for premature babies' participation rights is feasible in the experience of some adults who know and care for babies, and treat them as people who can to some extent form and express relevant views.

Babies' rights hold immediate and urgent messages in being the means to set and assess standards of care in neonatal units that promote the babies' health and welfare, and the family relationships on which they so greatly depend. The protection, 
provision and participation UNCRC articles are integral and key concerns in NICU policy and practice, whether they are explicitly honoured or not, and because the rights are sometimes disregarded, attention to the UNCRC is an indispensable guide to high standards of neonatal care.

The traditional language of children's interests, needs and welfare tends to emphasise children's passive helpless dependence on adults' choices. The newer language of children's rights, especially of participation, acknowledges that children too can be informed choosers, agents and contributors with views that can guide and inform individual baby's care and wider neonatal policies and practices. Babies participate by sharing in the creation and growth of families and communities. More than actors, babies can be agents who alter relationships, decisions and the working of social assumptions or constraints (Mayall, 2002:21). The understanding of babies' rights grows through the understanding of babies' aware consciousness within human relationships; these two understandings can justify and validate one another. When babies are accepted to have a certain degree of consciousness, certain obligations by adults follow: to value the babies' present life now, besides their potential and future; and to try to hear and respect babies' views.

In some ways, it is more important that adults respect what they understand to be babies' views and rights, than that they try to prove that babies have an arbitrary level of consciousness high enough to count as a human-rights-holding personhood, because rights partly become real in being respected, just as babies learn to speak through being spoken to for months as if they can already speak. Conversely, the rights and autonomy of highly competent adults can be denied and ignored, in the example of prisoners of conscience, so that rights exist in perception and relationship besides in objective reality. Children's rights also exist in an independent reality in the very carefully worded UNCRC, by far the most widely agreed international treaty. And by ratifying the Convention in 1991, the British government undertook to implement it. The UNCRC speaks of all members of the human family, a continuum of life without discrete stages, and the expressive views of premature babies illustrate how inclusive and diverse the UNCRC participation rights can be. Freeman (2002) reviews how normative rights become convincing neither through truth claims nor through subjective preferences, but through Kantian concepts of communal or universal "common sense" that imaginatively respects other people's perspectives or standpoints and their common humanity. This paper has aimed to imagine premature babies' human perspectives, and also to suggest integral, embodied, and commonly sensed bases for the rights of every member of the human family.

\section{Acknowledgements}

We are grateful to all the families and staff in the neonatal units who helped with the research, "Foretelling Futures: dilemmas in neonatal neurology", to Inga Warren, the Advisory Group, the four Local Research Ethics Committees that approved the project, and the Wellcome Trust Bioethics Programme for funding project no. 066458.

\section{References}

Alanen, L., "Explorations in Generational Analysis", in Alanen, L., Mayall, B. (eds) Conceptualizing Child-Adult Relations (London: Routledge Falmer, 2001).

Alderson, P., Young Children's Rights (London: Jessica Kingsley, 2000).

Alderson, P., "Are Premature Babies Citizens with Rights?" Journal of Social

Science, (in press).

Alderson, P., "Premature Babies' Protection Rights", (forthcoming).

Alderson, P., "Nurses and Informed Consent", (forthcoming a).

Alderson, P., Hawthorne, J., Killen, M., Foretelling Futures: Dilemmas in Neonatal Neurology. End of project report (London: SSRU, Institute of Education, 2004). 
Als, H., Manuel for the Naturalistic Observation of the Newborn (Preterm and Full Term) (Boston: Children's Hospital, 1981).

Als, H., "Reading the Premature Infant", in E. Goldson (ed) op. cit., (1999), pp 18-85. Anderson, G., "Kangaroo Care of the Premature Infant", in E. Goldson (ed) op.cit.,(1999), pp 131-160.

Bell, R., "A Reinterpretation of the Direction of Effects in Studies of Socialization", Psychological Review, 1968 (75), 81-95.

BMA. - British Medical Association, Withholding and Withdrawing Life Prolonging Medical Treatment (London: BMA, 2001).

Bond, C., Positive Touch (London: St Mary's Hospital, 2002).

Boxwell, G. (ed), Neonatal Intensive Care Nursing (London: Routledge, 2000).

Brazelton, T., "Psychophysiologic Reactions in the Neonate. 1. The Value of

Observation of the Neonate", Journal of Pediatrics 1961 (58), 508-512.

Brazelton, T., "Introduction", in T. Brazelton and J. Nugent (eds) op. cit.,(1995) pp 1-

6.

Brazelton, T., Nugent, J. Neonatal Behavioral Assessment Scale, 3rd edition. Clinics in Developmental Medicine no. 137, (London: MacKeith Press/CUP, 1995).

Bruner, J., Acts of Meaning (Cambridge MA: Harvard University Press, 1990).

Dunn, J., "The Beginnings of Moral Understanding", in J. Kagan, S. Lamb (eds) The

Emergence of Morality in Younger Children (Chicago: University of Chicago Press, 1987).

Fifer, W., Moon, C., "The Role of the Mother's Voice in the Organization of Brain

Function in the Newborn", Acta Paediatrica, Suppl. 1994 (397), 86-93.

Fischer, K., Rose, S., "Dynamic Development of Coordination of Components in Brain and Behaviour: a Framework for Theory and Research", in G. Dawson, K. Fischer (eds) Human Behaviour and the Developing Brain (New York: Guilford Press, 1994) pp $3-66$.

Freeman, M., "Human Rights, Children's Rights and Judgement", International Journal of Children's Rights 2002 (10), 345-354.

Gardner, H., The Unschooled Mind (London: Fontana, 1993).

Glass, P., "Role of Light Toxicity in the Developing Retina Vasculature", Birth Defects 1988 (24), 103-117.

Glass, P., 1993 "Development of Visual Function in Preterm Infants", Infants and Young Children 1993 (6), 11-20.

Goldson, E., (ed) Nurturing the Premature Infant (New York: Oxford University Press, 1999).

Gottfried, A., "Environment of Newborn Infants in Special Care Units", in A. Gottfried, J. Gaiter (eds) Infant Stress Under Intensive Care (Baltimore: University Park Press, 1985) pp 23-54.

Graven, S., Bowen, F., Brooten, D., Eaton, A., et al, "The High-Risk Infant

Environment", Journal of Perinatology 1992 (12), 164-72.

Greenfield, S., The Private Life of the Brain (London: Penguin, 2000).

Harris, J., The Value of Life (London: Routledge and Kegan Paul, 1985).

Holt, J., Escape From Childhood (Harmondsworth: Penguin, 1975).

HRA - Human Rights Act (London: Stationery Office, 1998).

Hutchby, I., Moran Ellis, J., (eds) Children and Social Competence. (London: Falmer, 1998).

James, A., Prout, A., Constructing and Reconstructing Childhood (London:

Routledge Falmer, 1997).

Killen, M., Alderson, P., Hawthorne, J., "Fathers in Neonatal Units", (forthcoming).

Lagercrantz, H., "Opening Address: the Development of Preterm Infants",

International Conference on Infant Development in Neonatal Intensive Care (London, 2003). 
Linn, P., Horowitz, F., Buddin, B., Leaker, J., Fox, H., "An Ecological Description of a Neonatal Intensive Care Unit", in A. Gottfried, J. Gaiter (eds) Infant Stress Under Intensive Care (Baltimore: University Park Press, 1985), pp 83-111.

Mann, N., Haddow, R., Stokes, L., Goodley, S., Rutter, N., "Effect of Night and Day on Preterm Infants in a Newborn Nursery: Randomized Trial", British Medical Journal 1986 (293), $1265-7$.

Mattiesen, A., Ransjo-Arvidson, A., Nissen, E., Uvnas-Moberg, K., "Postpartum Maternal Oxytocin Release by Newborns: Effects of Infant Hand Massage and Sucking", Birth 2001 (28,1),13-9.

Mayall, B., Towards a Sociology for Childhood (London: Routledge Falmer, 2002). McHaffie, H., Crucial Decisions at the Beginning of Life. (London: Routledge 2001). Montgomery, J., Health Care Law (Oxford: Oxford University Press, 1997).

Murdoch, D., Darlow, B., "Handling During Neonatal Intensive Care", Archives of Disease in Childhood 1984 (59), 957-61.

Murray, L., Andrews, L., The Social Baby (Richmond: Children's Project Publishing, 2000).

Odent, M., The Scientification of Love (London: Free Association Books, 1999).

Philbin, K., Robertson A, Hall J, "Recommended Permissible Noise Criteria for Occupied, Newly Constructed or Renovated Hospital Nurseries", Journal of Perinatology 1999 (1), 559-563.

Purves, D., Neural Activity and the Growth of the Brain (Cambridge: Cambridge University Press, 1994).

QCA - Qualifications and Curriculum Authority, Education for Citizenship and the Teaching of Democracy in Schools (Crick Report) (London: DfEE/QCA, 1998).

$\mathrm{RCPCH}-$ Royal College of Paediatrics and Child Health, Withdrawing or Withholding Life Saving Treatment in Children (London: RCPCH, 1997).

$\mathrm{RCPCH}$, Prevention and Control of Pain in Children (London: RCPCH, 1997a).

RCOG - Royal College of Obstetricians and Gynaecologists, A Consideration of the

Law and Ethics in Relation to Court Authorised Intervention (London: RCOG, 1994).

Shatz, K., "Dividing up the Neocortex", Science 1992 (258), 237-8.

Siegal, M., Knowing Children (Hove: Lawrence Erlbaum Associates, 1997).

Singer, P., Rethinking Life and Death (Oxford; Oxford University Press, 1995).

Strauss, A., and Corbin, J. Basics of Qualitative Research (London: Sage, 1998).

Symington, A., Pinelli, J., "Developmental Care for Promoting Development and

Preventing Morbidity in Preterm Infants" (Cochrane Database Systematic Review, 2000) (4): CD001814.

UNCRC United Nations, Convention the Rights of the Child (Geneva: UN, 1989). Vygotsky, L., Thought and Language (Boston: MIT Press, 1962).

Warren, I., (ed) Guidelines for Infant Development in the Newborn Nursery. Third Edition (London: St Mary's Hospital, 2001).

White, R., "Design of Intensive Care Units", Pediatrics 1992 (89), 1267.

Wolke, D., "Parents' Perceptions as Guides for Conducting NBAS Clinical Sessions", in B. Brazelton, T. Nugent, (eds) op. cit. (1995) pp. 117-125.

Wolke, D., "Environmental Neonatology", Archives of Disease in Childhood 1989 (62), 987-88.

Wyatt, J., Matters of Life and Death (Leicester: Inter-varsity Press, 1998). 